\title{
ALTMUNIR Jurnal Komunikasi dan Penyiaran Islam
}

\author{
Jurnal Komunikasi dan Penyiaran Islam \\ Vol. 9, No. 2, Juli-Desember 2018
}

\section{Komunikasi Humanis dan Termanifestasikan Yang Berkeadaban Patrioteisme Kebangsaan Untuk Tatanan Beragama Yang Tatanan Sosial Berkeadaban Demokrasi Penulis : Zike Marta \\ Sumber : Jurnal Komunikasi dan Penyiaran Islam, Vol. 9, No. 2, Juli - Desember 2018 \\ Diterbitkan Oleh : Prodi Komunikasi dan Penyiaran Islam}

\section{Untuk Mengutip Artikel ini :}

Zike Marta, 2018. Komunikasi Humanis dan Termanifestasikan Yang Berkeadaban Patrioteisme Kebangsaan Untuk Tatanan Beragama Yang Tatanan Sosial Berkeadaban Demokrasi. Al Munir Jurnal Komunikasi dan Penyiaran Islam, Vol. 9, No. 2, Juli-Desember 2018, p. 123-129

Copyright (C) 2018, Jurnal Komunikasi dan Penyiaran Islam ISSN : e-ISSN : 2657-0521

ISSN : p-ISSN : 2086-1303

Prodi Komunikasi dan Penyiaran Islam FDIK UIN Imam Bonjol Padang






\title{
Komunikasi Humanis dan Termanifestasikan Yang Berkeadaban Patrioteisme Kebangsaan Untuk Tatanan Beragama Yang Tatanan Sosial Berkeadaban Demokrasi
}

\author{
Zike Marta $^{1}$ \\ ${ }^{1}$ UIN Imam Bonjol Padang \\ Email : zikemarta17@gmail.com
}

\begin{abstract}
Guidance for democracy and national patriotism, both political and social, has become a universal agenda among the components of civil society (Civil Society), almost all parts of the world cannot be separated from the global guidance of this democracy, including Indonesia. In everyday political and social life, social behavior and political practice of the community are still often carried out with actions that are far from the noble values of Pancasila and democracy. Democracy which is a commitment of the reform movement is still filled with a culture of corruption and collusion committed by the community and officials. They want to be formal leaders and leaders of community and professional organizations. According to the author, the values of the principles of democracy can actually be practiced through the study of humanist democracy in higher education courses which are expected to be a laboratory to implement democratic principles that are integrated with the principles and values of universal democracy with the values of Pancasila
\end{abstract}

Keywords: communication; democracy; humanism

\begin{abstract}
ABSTRAK
Tuntunan akan demokrasi dan patriotisme kebangsaan, baik politik, maupun sosial telah menjadi agenda bersama yang bersifat universal di kalangan komponen masyarakat madani (Civil Siciety), hampir selurh belahan dunia tidak bisa lepas dari tuntunan global demokrasi ini, termasuk Indonesia. Dalam kehidupan politik dan sosial sehari-hari, perilaku sosial dan praktik politik masyarakat masih kerap dilakukan dengan tindakan-tindakan yang masih jauh dari nilai luhur pancasila dan demokrasi. Demokrasi yang menjadi komitmen gerakan reformasi masih disesaki oleh budaya korupsi dan kolusi yang dilakukan oleh masyarakat dan aparat. Mereka ingin menjadi pemimpin formal maupun pemimpin organisasi masyarakat dan profesi. Menurut penulis nilai-nilai prinsip demokrasi yang sesungguhnya dapat dipraktikkan melalui pembelajaran demokrasi humanis di mata kuliah perguruan tinggi yang diharapkan mampu menjadi laboratorium untuk menerapkan prinsip-prinsip demokrasi yang terintegrasi dengan prinsip dan nilai demokrasi universal dengan nilai pancasila
\end{abstract}

Kata Kunci : komunikasi; demokrasi; humanis 


\section{PENDAHULUAN}

Dalam Konteks pendidikan nasional, sebagai wadah instrumen untuk mewujudkan yaitu "berkembangan potensi peserta didik agar menjadi manusia yang beriman dan bertakwa kepada Tuhan yang Maha Esa, Berakhlak mulia, sehat, berilmu, cakap dan kreatif, mandiri dan menjadi warga negara yang demokratis serta bertanggung jawab" bersandar pada diktum perundangan ini. Pada dasarnya merupakan sebuah instrumenpendidikan yang mencerdaskan kehidupan bangsa, mengembangan kemampuan dan membentuk watakserta peradaban bangsa yang bermartabat.

Prof. Dr. Satryo Soemantri Brodjonegoro dalam bukunya edisi revisi tahun 2014, menyatakan bahwa hakikat pendidikan tinggi mempunyai fungsi untuk membentuk sosok lulusan yang utuh dan lengkap ditinjau dari segi kemampuan/kesiapan pribadi dimana fungsi pendidikan itu antara lain:

a. Menghasilkan lulusan Manusia yang mampu bertanggung jawab terhadap segala kebutuhan untuk aktivitas manusia.

b. Memberikan kesempatan untuk belajar sepanjang hayat, memberikan kemudahan untuk masyarakat yang ingin belajar dalam berbagai bidang

c. Memajukan, menciptakan dan menyebarluaskan pengetahuan melalui penelitian dan menyediakan keahlian yang relevan untuk membantu masyarakat dalam hal pengembangan budaya, sosial dan ekonomi, promosi dan pengembangan kegiatan penelitian dalam berbagai bidang termasuk seni.

d. Membantu

pemahaman, menginterprestasikan, promosi dan penyebarluaskan budaya historis, budaya nasional, regional dan internasional dalam konteks komunikasi kultural dan kebhinekaan.

e. Membantu melindungi dan meningkatkan nilai sosial melalui pendidikan generasi muda mengenai nilai demokrasi kemasyarakatan dan peningkatan humanisme.

f. Kontribusi terhadap pengembangan dan peningkatan melalui bidang pendidikan.

Dalam menyapai hal di atas beserta seluruh unsurnya bisa diperlukan:

a. Melestarikan dan pengembangan fungsi etika komunikasi dan nilai intelektual dalam setiap aktifitas.

b. Mampu menyarakan etika komunikasi, budaya dan sosial secara independen dan penuh kesadaran akan bertanggung jawab intelektual.

c. Meningkatkan kapasitas inteklektual dan moral untuk mempertahankan dan menyebarluaskan nilai universal termasuk kedamaian, penegakan hukum, kebebasan, persamaan hak dan solidarias.

d. Mempunyai kebebasan dan otonomi akdemik secara penuh kepada masyarakat

e. Mempunyai Peran dalam mengindtifikasikan dan menyampaikan isu yang mempengaruhi kemajuan komunitas, bangsa dan masyarakat global.

Serta berdasarkan undang -undang Nomor 2 tahun 1989, tentang pendidikan Pancasila merupakan yang harus diikuti peserta pendidikan tinggi di Indonesia. Mengingat yang terjadi pada saat ini sebagai akibat dari proses demokrasi dan sesuaian denga hakikat pendidikan serta pengembangan filosopi untuk kepentingan dan pengembangan kepribadian.

Untuk diarahkan kepada paradigma pengembangan hukum, paradigma keilmuan, paradigma ketahanan dan keamanan dan paradigma pengenbangan ekonomi, agar supremasi penegak hukum dan perspektif pengembangan Hak Asasi Manusia. 


\section{PEMBAHASAN}

Tuntunan akan demokrasi dan patriotisme kebangsaan, baik politik, maupun sosial terlah menjadi agenda bersama yang bersifat universal dikalangan komponen masyarakat madani (civil siciety), hampir selurh belahan dunia tidak bisa lepas dari tuntunan global demokrasi ini. Tak terkecuali Indonesia, keingginan untuk menjadi bagian dalam pecaturan masyarakat dunia sebagaimana yang dicita-citakan oleh konstitusi nasional, pada saat yang sama tidak ingin kehilangan jati diri serta nilai - nilai luhur yang terkandung dalam empat pilar kebangsaan disamakan juga dengan empat pilar konsesus nasionalnya: Pancasila, Undang-Undang Dasar tahun 1945(UUD45), Bhineka Tunggal Ika, Dan Negara Kesatuan Republik Indonesia (NKRI)

Sejak Era Reformasi 1998, banyak hal yang sudah berubah, namun masih terlalu banyak yang harus dibenahi dalam tata kelola kehiduan berbangsa dan bernegara. Dalam kehidupan politik dan sosial sehari-hari, perilaku sosial dan praktik politik masyarakat masih kerap dilakukan dengan tindakan-tindakan yang masih jauh dari nilai luhur pancasila dan demokrasi. Politik uang (Money Politics) dan suap menyuap dalam praktik politik dan hukum yang membanggkrutkan sendi-sendi moral bangsa dan demokrasi masih menjadi kendala paling serius bagi gerakan yang ada di Indonesia.

Demokrasi yang menjadi komitmen gerakan reformasi masih disesaki oleh budaya korupsi dan kolusi yang dilakukan oleh masyarakat dan aparat dan mereka ingin menjadi pemimpin formal maupun pemimpin organisasi masyarakat dan profesi. Jika hal ini dilanggengkan menurut penulis demokrasi tak akan memenuhi janjinya, yakni kesejahteraan bagi masyarakat luas. Sebaliknya demokrasi hanya menjadi kepanjangan tangan bagi mereka yang memiliki modal dan akses kekuasaan. Demokrasi telah dibajak oleh mereka yang beruntung oleh sistem kekuasaan masa lalu yang sarat KKN.

Jika praktik-praktik koruptif ini tetap ditoleransikan oleh masyarakat, tidak mustahil indonesia akan mengalami proses demoralisasi kolektif selain dilanda defisit panutan dan negarawan. Konsekuensi logis dari penyakit moral dan pembelokan atas janji-janji reformasi ini adalah peluang munculnya ketidakpuasan masyarakat yang menyalut tindakan-tindakan anarkis sosial. Namun demikian, hal ini bisa dihindari dengan komitmen semua pihak, terutama kalangan birokrasi dan kelas menengah Indonesia, untuk membudayakan politik bersih, aman dan murah.

Membangun tradisi politik bersih dan murah sangatlah mendesak bagi Indonesia sekarang demi masa depan demokrasi yang lebih substantif. Untuk mewujudkan tradisi ini. Pendidikan politik dilakukan oleh pemerintah maupun partai politik dan organisasi masyarakat melalui pola pembelajaran komunikasi yang humanis dan demokrasi merupakan salah satu cara yang amat dibutuhkan masyarakat saat ini.

Menurut penulis dimana nilai-nilai prinsip demokrasi yang sesungguhnya dapat di praktikan melalui pembelajaran demokrasi humasnis di mata kuliah perguruan tinggi yang diharapkan mampu menjadi laboratorium bagi pembumian prinsip-prinsip demokrasi yang terintegrasi antara prinsip dan nilai demokrasi universal dengan nilai pancasila, misalnya yang diharapkan penulis demokrasi dan Pancasila bukan sesuatu yang jauh dan hidup dalam wacana, namun keduanya hadir dalam kehidupan sehari-hari pada akhirnya menjadi unsur komunikasi dari identitas dan karakter nasional Indonesia.

$$
\text { Komunikasi dengan bijakan }
$$
pembangunan karakter bangsa ini sangat 
relevan untuk dilakukan saat ini dimana prilaku berdemokrasi di Indonesia, masih banyak disalahpahami oleh warga negara Indonesia. Komunikasi demokrasi masih banyak dipahami sebatas kebebasan bertindak dan berekspresi tanpa menghiraukan hak-hak asasi orang lain. Bahkan dengan alasan demokrasi masyarakat dengan mudah bertindak anarkis dengan cara merusak fasilitas umum, saat melakukan demonstrasi, tanpa menyadari akan kewajiban menjaga ketertiban sosial. Jika Hal Itu dibiarkan berlangsung demokrasi yang tengah diperjuangkan nasibnya di Indonesia akan kehilangan nilai etisnya sebagai nilai yang harus dikomunikasikan dan dijaga bersama-sama setiap warganegara.

Dalam tatanan kebangsaan, ilmu komunikasi dan demokrasi akan bernilai rendah jika dalam pemahamannya dan impletasi merusak tatanan sosial dan nilai persatuan serta keragaman Indonesia. Sebagai sebuah negara bangsa yang didirikan dengan modal persamaan nasib serta cita-cita yang bersendikan nilai luhur yang terkristalkan ke dalam dasar negara Pancasila, demokrasi dalam berkomunikasi yang baik bisa menjaga karakter Indonesia yang majemuk.

Patriotisme kebangsaan menurut penulis dapat menjadi media pertemuan beragam nilai dengan khazanah pemikiran dan nilai Indonesia yang berakhir dengan lahirnya sebuah sintesis kreatif yang khas dan pas sebagai panduan bersama bangsa Indonesia

Indonesia demokrasi haruslah sejalan dengan unsur-unsur pendukung realisasi cita-cita proklamasi dan unsur penting dalam pembanguanan karakter manusia sebagaimana tertuang dalam empat pilarkebangsaan dan patriotisme.

Pancasila, Negara Kesatuan Republik Indonesia (NKRI), UUD45, dan Bhineka Tunggal Ika adalah harga mati bagi bangsa Indonesia. Keempat Pilar nasional ini harus bersinergi dengan demokrasi yang sudah menjadi pilihan bagi gerakan reformasi. Keragaman dalam persatuan yang tergambar dalam slogan Bhinega Tunggal Ika dalam Pancasila, Merupakan ruang kreatif bagi bangsa Indonesia untuk mensinergikan hal-hal yang baik di masa lalu dengan nilai yang prinsip demokrasi yang saat ini dinilai sebagai sistem politik paling baik di antara sistem-sistem yang pernah ada di dunia.

Prinsip kemajemukan dalam pancasila dapat bersinergi secara dinamis dengan prinsip-prinsip demokrasi yang lahir dan berkembang dari situasi sosial yang majemuk, sekalipun ia muncul dari tradisi Barat. Mempertentangan antara demokrasi dan falsafah Pancasila tentu saja tidak selamanya relevan dengan tata kehidupan masyarakat dunia yang semakin global. Kekhawatiran masyarakat akan hilangnya nilai-nilai gotong royong dan musyawarah mufakat akibat arus deras tuntunan demokrasi global sebaiknya komunikasi tidak serta merta menimbulkan sikap antipati terhadap demokrasi. Prinsip kemajemukan dalam persatuan Indonesia memberi ruang sah bagi munculnya pemikiran dan pandangan beragam, bahkan kemungkinan lahirnya tafsir pandangan baru atas Pancasila sekalipun.

Keragaman ini selalu ditoleransi dan dikomunikasikan oleh kelenturan falsafah Pancasila sepanjang tidak berlawanan dengan pesan moral kelima sila Pancasila dan melahirkan ancaman terhadap sendisendi kesatuan bangsa dan eksistensi NKRI.

Kemajemukan adalah suatu kenyataan yang tidak bisa dihindari oleh Indonesia sebagai sebuah bangsa yang besar. Pada saat yang sama kemajemukan tidak boleh sebagai pemicu hilangnya rasa persatuan Indonesia sebagai sebuah bangsa dan negara kesatuan.

Banyak ahli menggulirkan gagasan kembali ke Pancasila sebagai obat penawar bagi beragaman persoalan kebangsaan yang dihadapi Indonesia di era sekarang ini, satu di antaranya apa yang digagas oleh Azyumardi Azra, 
dengan gagasan revitalisasi Pancasila sebagai haluan bersama bangsa Indonesia dalam kehidupan berbangsa dan bernegara. Namun tidak cukup sampai di sini, komitmen ini harus dilanjutkan dengan tindakan nyata untuk mendekonstruksikan pendidikan Pancasila. Label Pancasila sebagai ideologi terbuka seyogyanya dibarengi dengan pembelajaran pendidikan pancasila melalui model-model dengan pendekatan komunikasi praktis dan kritis. Ia harus diletakkan sebagai sebuah situasi yang terus berubah dalam bingkai kemajemukan dalam sosialisasi komunikasi yang humanis dalam patriotisme kebangsaan.

\section{KESIMPULAN}

Warganegara sebagaimana subjek dari pada objek yang memiliki komunikasi yang humanis dan patriot kebangsaan kemudian termanifestasikan ke dalam tatanan sosial yang berkeadaban patrioteisme kebangsaan dalam tatanan beragama serta tatanan sosial yang berkeadaban demokrasi.

Jumlah warga negara yang masih awam atas subtansi demokrasi dan lalai terhadap posisi historis Pancasila bagi Indonesia menjadi alasan utama akan perlunya sebuah model pendidikan dalam komunikasi yang dapat mengetaskan lahirnya generasi Indonesia yang demokratis, berkarakter inklusif, berwawasan global namun tetap berpijak pada nilai-nilai ke-Indonesia-an yang baik. Kewarganegaraan yang lebih berorientasi pada pemberdayaan manusia dalam hidup secara damai.

Dengan mengalami demokrasi secara langsung ini diharapkan komunikasi dalam demokrasi secara langsung melalui pembelajaran yang kolaboratif dan kontekstual diharapkan persamaan kultur demokrasi di kalangan berbagai aspek dengan cirinya yang cerdas, aktif, kritis dan tak kalah pentingnya mereka juga harus menjadi kontributor bagi penyelesaian berbagai persoalan publik.

Untuk mewujudkan warga negara Indonesia yang berkarakter seperti pendekatan humanistik dan pembelajaran kolaboratif atau diharapkan mampu melahirkan warga negara Indonesia kini dan mendatang yang demokratis serta berkomunikasi dengan baik, terbuka dan berkarakter keadaban.

\section{DAFTAR KEPUSTAKAAN}

Ardianto, Elvinaro dan Lukiati Kumala Erdinaya, 2004, Komunikasi Massa Suatu Pengantar, Simbiosa Rekatama Media, Bandung

Berger, Charles R and Steven H. Chafee, 1985, Hand Book of Communication Scene, Sage Publications, London

Cangara, Hafied, 2004, Pengantar Ilmu Komunikasi, Raja Grafindo Indonesia, Jakarta

Effendy, Onong Uchjana, 1998, Hubungan Masyarakat Suatu Studi Komunikologis, Rosdakarya, Bandung

Effendy, Onong, 2003, Ilmu Komunikasi Teori dan Praktik, PT Remaja Rosdakarya, Bandung

Faisal, Sanafiah, 1990. Penelitian Kualitatif Dasar-Dasar dan Aplikasi, Yayasan Asih Asah Asuh, Malang

Griffin, E.M., 2006, A First Look at Communication Theory, Sixt Edition, Mc Graw-Hill International, New York Indriati, M.T., 2007, A to Z The Golden Age, Penerbit Andi, Yogyakarta

Jefkints, Frank, 2002, Public Relations, Edisi Kelima, Penerbit Erlangga, Jakarta

Kasali, Renald, 1995, Manajemen Periklanan Konsep dan Aplikasinya di Indonesia, Pusat Antar Universitas Ekonomi UI, Grafiti, Jakarta

Kasali, Renald, 2007, Membidik Pasar Indonesia Segmentasi, Targeting, Positioning, Gramedia, Jakarta 
Kotler, Philip and Eduardo L. Roberto, 1989, Social Marketing Strategies for Changing Behavior, The Free Press, New York

Kotler, Philip, 2000, Marketing Management, International Edition, The Prentice Hall, New Jersey

Kriyantono, Rachmat, 2007, Riset Komunikasi, Kencana Prenada Media Grup, Jakarta

Lee, Monle and Carlo Johnson, 2004, Prinsip-prinsip Pokok Periklanan dalam Perspektif Glonal, Diterjemahkan Hary Munandar dan Dudy Priatna, Drenada, Jakarta

Moffit, Mary Anne, 1999, Campaign Strategies and Message Design, Praeger Publisher, USA

Mulyana, Deddy, 2007, Ilmu Komunikasi Suatu Pengantar, Edisi Revisi, PT Remaja Rosdakarya, Bandung

Mulyana, Deddy, 2006, Metode Penelitian Kualitatif, PT Remaja Rosdakarya, Bandung

Munter, Mary, 2002, Guide to Managerial Communication Effectif Business Writing and Speaking, Six Edition, Prentice Hall, New Jersey

Nasution, Zulkarimen, 1998, Komunikasi Pembangunan Pengenalan Teori dan Penerapannya, Edisi Revisi, PT Raja Grafindo Persada, Jakarta

Nawawi, Hadari dan Mimi Martini, 1994, Penelitian Terapan, Gajah Mada University Press, Yogyakarta 